\title{
NATURALEZA DE LA RESPONSABILIDAD PRECONTRACTUAL (CULPA IN CONTRAHENDO) EN LA ARMONIZACIÓN JURÍDICA EUROPEA
}

\section{GEMA TOMÁS MARTÍNEZ*}

RESUMEN: Este artículo examina la naturaleza de la culpa in contrahendo con especial atención a los tratos preliminares. Este es un aspecto controvertido en los países europeos y actualmente en el ámbito de la armonización jurídica europea. El enfoque legal moderno en los derechos nacionales europeos es muy distinto y hay diferencias relevantes entre los que consideran la culpa in contrahendo en el ámbito del derecho de contratos o los que lo enmarcan entre los delitos o cuasidelitos o incluso quienes lo conciben como un tertium genus. Los trabajos académicos para la armonización del derecho civil europeo, como el denominado Marco Común de Referencia Europeo (DCFR) o los Principios Europeos del Derecho de Contratos (PECL) han adoptado el principio de buena fe aplicable a las negociaciones precontractuales y sus consecuencias, pero estos trabajos no clarifican la naturaleza de esta responsabilidad y tampoco utilizan explícitamente la expresión culpa in contrahendo. El Reglamento europeo sobre la ley aplicable a las obligaciones no contractuales (Roma II) recoge una regla específica sobre la culpa in contrahendo. Esta responsabilidad es considerada como un concepto autónomo pensado solo para el derecho europeo y a pesar del hecho de que la regla de conflicto aplicada a las obligaciones no contractuales de acuerdo con esta regulación es la ley del lugar donde se ha cometido el hecho dañoso, la ley que se aplicará a los supuestos de culpa in contrahendo será la ley del contrato.

PALABRAS CLAVE: Responsabilidad precontractual - culpa in contrahendo - buena fe - ruptura injustificada de las negociaciones armonización jurídica europea.

Doctora en Derecho, Profesora Titular de Derecho Civil y Derecho Romano, Universidad de Deusto (España). Correo electrónico: gtomas@der.deusto.es

Fecha de recepción: 1 de marzo de 2010.

Fecha de aprobación: 27 de julio de 2010. 


\title{
Nature of the Precontractual Liability (CULPA IN CONTRAHENDO) IN THE EUROPEAN JURIDICAL HARMONIZATION
}

\begin{abstract}
This article examines the nature of culpa in contrahendo with special attention to precontractual agreements. This is currently a controversial aspect in European countries in the scope of the European juridical harmonization. The modern legal focus in the European national Law is very different and there are relevant differences among those who consider culpa in contrahendo in the scope of Contracts and those who place it with crime or quasicrime or even those who consider it as tertium genus. Academic work for the harmonization of the European civil law, such as the Draft Common Frame of Reference (DCFR) or the Principles of European Contract Law (PECL) have adopted the principle of good faith applicable to precontractual negotiations and their consequences, but these pieces of work do not clarify the nature of this liability nor do they explicitly use the expression culpa in contrahendo. The European Regulation regarding the applicable law to non-contractual obligations (Rome II) reflects a specific norm about culpa in contrahendo. This liability is regarded as an autonomous concept thought of only for the European Law and, despite the fact that the rule of conflict applied to non-contractual obligations according to this regulation is the law of the place where the tort has been committed, the law that shall apply to the suppositions of culpa in contrahendo will be the contract law.
\end{abstract}

KEY WORDS: Precontractual liability - culpa in contrahendo good faith - unjustified rupture of negotiations - european juridical harmonization.

\section{INTRODUCCIÓN}

Casi todo en el ámbito de la responsabilidad precontractual ha estado siempre bajo discusión: el fundamento de la misma, en cuanto a si es contractual, no contractual o si estamos ante un tertium genus, es uno de los puntos más controvertidos, pero no el único. Se debate también sobre los principios que están implicados en ella como la buena fe, neminem laedere, el abuso de derechos, la equidad, fair dealing o justa negociación, etc.; también sobre el alcance de la indemnización (interés negativo o de confianza o bien interés positivo o de cumplimiento); el plazo para reclamar responsabilidad; la exigencia de culpa; la prueba en caso de procedi- 
miento judicial, etc. Incluso la clásica expresión culpa in contrahendo se evita con cierta frecuencia últimamente y se sustituye por la más "neutral" de responsabilidad precontractual.

Lo que denominamos culpa in contrahendo, en un sentido amplio, cubre diferentes situaciones como la nulidad de contrato por dolo o fraude empleado por una de las partes contra la otra, la falsa representación, los daños personales o pérdidas económicas ocasionadas en la fase de negociaciones preliminares (ruptura injustificada de negociaciones, deberes de información e información confidencial revelada). Actualmente, la expresión responsabilidad precontractual se concentra cada vez más en el ámbito de esta última, es decir, en los deberes que las partes asumen en la fase precontractual, sobre los cuales se centra también esta contribución, con especial atención al fundamento de la culpa in contrahendo, a lo largo de los tratos preliminares.

Estamos ante un tema controvertido en los diferentes ordenamientos jurídicos y por lo tanto en estos tiempos de armonización europea se está haciendo un esfuerzo por recoger los aspectos más importantes en los que hay cierto consenso.

Vamos a prestar atención a cuatro referencias importantes en este ámbito: de un lado, los Principios Europeos de Derecho de contratos (Principles of European Contract Law, conocidos como PECL) y el borrador de Marco Común de Referencia (Draft of a Common Frame of Reference, conocido por sus siglas DCFR) que fue presentado en la Comisión europea a finales de diciembre de $2007^{1}$, ninguno de estos dos documentos tienen valor normativo.

Por otro lado, los Reglamentos comunitarios sobre reglas aplicables a las obligaciones contractuales y no contractuales (Roma I y Roma II) ${ }^{2}$.

La expresión culpa in contrahendo fue forjada por Jhering en 1861 con el fin de referirse con ella a la responsabilidad en el periodo precontractual $^{3}$. La teoría de Jhering fue el resultado de la aplicación del método de la conocida como jurisprudencia de conceptos sobre la base de fuentes romanas relacionadas con la venta de res extra commercium cuando el vendedor conoce esta naturaleza de la cosa y no informa de este aspecto

1 Von Bar, Christian et alii (eds.) (2008). Principles. Definitions and Model Rules of European Private Law. Draft Common Frame of Reference (DCFR). Interim Outline Edition preparada por el Study Group on European Civil Code y el Research Group on EC Private Law, Munich: ed. Sellier - European Law Publishers. Von BAR, Christian (2005). "Working together toward a Common Frame of Reference”, JI (Juridica International), No X, pp. 17-26.

2 DOUE L199/40, 31 julio 2007.

3 Von Jhering, R. (1861). "Culpa in contrahendo oder Schadensersatz bei nichtigen oder nicht zur Perfektion gelangten Verträgen”, Jherings Jahrbücher für die Dogmatik des heutigen römischen und deutschen Privatrechts, No 4, pp 1-113. 
al comprador. Según las fuentes romanas, el comprador de buena fe tiene una acción contractual para obtener el id quod interest. Puede decirse que esto es así al menos en la etapa del derecho romano clásico tardío ${ }^{4}$.

Así se desprende de dos importantes fragmentos del Digesto: D. 11, 7, 8,1 (Ulp., ad ed. 25) sobre la venta de una res religiosa; D. 18, 1, 62,1 (Mod., Reg. 5$)^{6}$ relativo a la venta de una res religiosa, sacra of publica; y un texto más que encontramos en las Instituciones de Justiniano: Instituta 3, 23, 5, sobre res religiosa o publica. ${ }^{7}$ Se considera a Modestino como el primer jurista en conceder acción contractual al comprador de un bien religioso.

Estas fuentes romanas y la interpretación de Jhering han dado lugar a enfoques muy diferentes en los sistemas jurídicos que hacen de la armonización una tarea nada fácil ${ }^{8}$.

4 Zimmermann, R. (1996). The law of obligations. Roman Foundations of the Civilian Tradition, Oxford: Clarendon Press, pp. 11-12 y p. 244, afirma que "la diligencia contractual que Jhering postulaba era debida no solo allí donde el contrato había llegado a existir sino también en el period statu nascendi. Con el comienzo de las negociaciones, las partes están entrando dentro de una relación (cuasi) contractual que genera derechos y deberes" (traducción propia).

5 D. 11,7,8,1. Ulpianus, ad ed libro vicensimo quinto ad edictum. Si locus religiosus pro puro venisse dicetur, praetor in factum actionem in eum dat ei ad quem ea res pertinet: quae actio et in heredem competit, cum quasi ex empto actionem contineat (Si se dijese que un suelo religioso fue vendido como puro, el pretor da a favor del dueño del lugar y contra el vendedor la acción por el hecho. Esta acción se da también contra el heredero, ya que se considera como si comprendiera la acción de compra). Se toma la traducción del Digesto de D’ors, Álvaro et alii (1968-1976). El Digesto de Justiniano, vol I., Pamplona: Aranzadi.

6 D. 18, 1, 62,1. Modestinus libro quinto regularum. Qui nesciens loca sacra vel religiosa vel publica pro privatis comparavit, licet emptio non teneat, ex empto tamen adversus venditorem experietur, ut consequatur quod interfuit eius, ne deciperetur (El que compró, ignorándolo, lugares sacros, religiosos o públicos, por privados, aunque la compra no se mantenga, no obstante podrá ejercitar la acción de compra contra el vendedor por su interés en no sufrir el engaño). D’ors (1968-1976).

7 Instituta Iustinianus. 3,23,5: Loca sacra vel religiosa, item publica, veluti forum basilicam, frustra quis sciens emit, quas tamen si pro privatis vel profanis deceptus a venditore emerit, habebit actionem ex empto, quod non habere ei liceat, ut consequatur, quod sua interest deceptum non esse. Idem iuris est, si hominem liberum pro servo emerit (A sabiendas, inútilmente compra uno lugares sagrados o religiosos, y también públicos, como un foro, una basílica, pero si engańado por el vendedor los hubiere comprado como profanos o privados, tendrá la acción de compra, porque no le era lícito tener la cosa para conseguir lo que le importe no haber sido engańado. Y el mismo derecho se aplica, si hubiere comprado un hombre libre por un esclavo).

8 Puede verse un panorama general sobre responsabilidad precontractual: VAN ERP, J.H.M. (2003). "European "culpa in contrahendo" doctrine? Towards a model of contract as a legal relationship and situation-specific duties to inform", Bases de un Derecho contractual europeo, Valencia: Tirant lo Blanch, pp. 67-77, y VAN ERP, J.H.M. (1998). "The precontractual stage", en Hartkamp et alii: Towards an European Civil Code, Nijmegen-The Hague-London-Boston: Ars Aequi, pp. 363 y ss.; Hondius, Ewoud (1991). Precontractual liability, Deventer: Kluwer Law International; Cartwright, J. / Hesselink, M. (ed.) (2009). Precontractual liability in European private law, Oxford: Cambridge University Press. 


\section{1) Panorama Legal europeo ACERCA DE LA Llamada CULPA IN CONTRAHENDO}

La forma en la que en cada país europeo ha abordado la responsabilidad precontractual es muy diferente. Para empezar hay ordenamientos en los que existe una regulación legal como es el caso de Alemania ${ }^{9}$, Italia ${ }^{10}$ y Portugal ${ }^{11}$, aunque no en todos ellos se incluyen las mismas situaciones que teóricamente pueden ser cubiertas bajo la clásica expresión.

De otra parte, hay sistemas jurídicos que ni siquiera tienen una referencia expresa en sus códigos civiles como acontece en Francia ${ }^{12}$,

9 No en el originario BGB, pero sí la reforma del BGB en materia de obligaciones (2001) ha incluido la culpa in contrahendo en parágrafo 311.2, con el tradicional perfil basado en el llamado contacto social (geschäftlicher Kontakt) y con un fundamento específico en el que la culpa juega el mismo papel que antes lo había hecho a través de la interpretación jurisprudencial. Ver BGB \$311. (2): Ein Schuldverhältnis mit Pfichten nach $\$ 241$ Abs. 2 entsteht auch durch:1. die Aufnahme von Vertragsverhandlungen. 2. die Anbahnung eines Vertrags, bei welcher der eine Teil im Hinblick auf eine etwaige rechtsgeschäftliche Beziehung dem anderen Teil die Möglichkeit zur Einwirkung auf seine Rechte, Rechtsgüter und Interessen gewährt oder ihm diese anvertraut, oder 3. ähnliche geschäftliche Kontakte). Medicus, D. (1986). "Zur Entdeckungsgeschichte der culpa in contrahendo", Fest. M. Kaser zum 80, Wien-Koln-Graz: Geburstag, pp. 169-180. El trabajo más interesante sobre culpa in contrahendo en Derecho español y otros sistemas europeos, principalmente el derecho alemán se encuentra en: Asúa GonzÁlez, C.I. (1989). La culpa in contrahendo (Tratamiento en el Derecho alemán y presencia en otros ordenamientos), Bilbao: Ediciones Universidad del País Vasco, 1989, y respecto a la reforma llevada a cabo en Alemania ver el trabajo: Asúa González, C.I. / Hualde Sánchez, J.J. (2003). "Codificación de la culpa in contrahendo en el Derecho alemán”, en VV. AA.: Estudios en Homenaje al Profesor Luis Diez-Picazo, vol. II, Madrid: Civitas, pp. 1415-1433.

10 Codice Civile (1942), art. 1.337: Trattative e responsabilità precontrattuale: Le parti, nello svolgimento delle trattative e nella formazione del contratto, devono comportarsi secondo buona fede $(1366,1375,2208)$. La responsabilidad precontractual fue introducida en Italia por Fagella, G. (1909). "Fundamento giuridico della responsabilitá in tema di trattative contrattuali”, Archivio Giuridico "F. Serafini”. Para una visión más contemporánea sobre el tema en derecho italiano ver: SAPONE, N. (2008). La responsabilità precontrattuale, Milán: Giuffrè; Di Donna, L. (2008). Obblighi informativi precontrattuale, vol. I (la tutela del consumitore), Milano: Giuffrè; Caruso, D. (1993). La culpa in contrahendo. L'esperienza statunitense e quella italiana, Milano: Giuffrè.

11 El Código portugués (1966), art. 227: Culpa na formação dos contratos: 1.Quem negoceia com outrem para conclusão de um contrato deve, tanto nos preliminares como na formação dele, proceder segundo as regras da boa fé, sob pena de responder pelos danos que culposamente causar à outra parte. 2. A responsabilidade prescreve nos termos do artigo 498. Ver Almeida Costa, M.J.B. (1999). Direito das Obrigaçoes, Coimbra: Almedina.

12 El Código francés (1804) no contempla ninguna previsión específica sobre tratos preliminares. En la doctrina el tema fue introducido por SAlEILles, R. (1907). "De la responsabilité contractuelle à propos d'une nouvelle étude sur la matière”, Revue Trimestrale Droit Civile, pp. 712 y ss. Ver: Coherier, C. (1939). Des obligations qui naissent des pourparlers préables a la formation des contrats, Paris: Publications Paris; Hilsenrad, A. (1934). Las obligaciones precontractuales, trad. de Menéndez Pidal, Madrid: Góngora; Schmidt, J. (1982). Negotiation et conclusion de contrats, Paris: Dalloz. Este tipo de dańos está cubierto por los artículos relativos a la responsabilidad extracontractual (arts. 1.382-3) aunque los tribunales han sido reacios a usar la expresión "responsabilidad precontractual". Suelen ser objeto de mención en la jurisprudencia la equidad y la doctrina del abuso del derecho. 
Países Bajos ${ }^{13}$-a pesar de su reciente codificación (1992-, Suiza ${ }^{14}$ o España ${ }^{15}$. En todos ellos, sin embargo, la responsabilidad precontractual

13 En los Países Bajos no hay una regla específica en el Código Civil (Burgerlijk Wetboek, 1992), sin embargo, tal responsabilidad precontractual se admite en la práctica de los tribunales, que la reconocen y aplican en sus decisiones. De hecho, la jurisprudencia ha ido identificando diferentes estadios dentro del periodo de negociación precontractual. En el primero de ellos, los tratos pueden romperse sin que de ello derive responsabilidad alguna. Pero en estadios sucesivos es más difícil. Si las negociaciones preliminares están ya en un punto avanzado y han generado cierto nivel de confianza en que el contrato se iba a celebrar, entonces la parte que rompa los tratos, debe pagar el interés negativo, e incluso si la ruptura llegara a acontecer en el momento de conclusión del contrato, las negociaciones no pueden ya romperse so pena de pagar el interés de cumplimiento o interés positivo -como si se tratara de responsabilidad contractual-. Ver sobre el tema Winkel, L. (2002). "Culpa in contrahendo in Roman law and in some modern Dutch court decisions", en VV. AA: Viva vox iuris romani. Essays in honour of Johannes Emil Spruit, Amsterdam: Gieben, pp. 149-157, con referencias también a la glosa de Accursio, a H. Grotius y al moderno derecho privado holandés.

14 El Código suizo no contiene ninguna regla específica sobre el tema y suele aplicarse un fundamento extracontractual con apoyo en los arts. 41 y sig. Véase Piotet, P. (1963). Culpa in contrahendo et Responsabilité précontractuelle en Droit privé suisse, Berna: ed. Staempli \& CIE, pp. 24-26.

15 El Código Civil español (1889) no contiene ninguna regla específica sobre responsabilidad precontractual y tampoco han llegado al Tribunal Supremo muchos asuntos de este orden. Cuando ello ha acontecido han sido resueltos como casos de responsabilidad extracontractual (art. 1.902). Así, la doctrina mayoritaria ha venido considerando los casos de responsabilidad precontractual como daños no contractuales en el sentido de infracción del principio neminem laedere. Podemos citar en este sentido a: Cabanillas Sánchez, A. (1995). "El ámbito de la responsabilidad precontractual o la culpa in contrahendo", Revista Critica de Derecho Inmobiliario, pp. 747-788; Carrasco Perera, A. (2006). "Cartas de intenciones, precontratos, responsabilidad in contrahendo y obligatoriedad de los tratos en la jurisprudencia espańola”, Aranzadi Civil, No 21, pp. 15-38; De los Mozos, J.L (2005). "Responsabilidad en los tratos preparatorios del contrato", en VV. AA: Estudios sobre Derecho de contratos, integración europea y codificación, Madrid: Dykinson, pp. 77-99 y en VV. AA: Libro-Homenaje al Prof. Roberto López Cabana, Madrid - Buenos Aires: Dykinson. No obstante, también se encuentran opiniones que por el contrario ven en la responsabilidad precontractual una suerte de responsabilidad contractual: Díez-Picazo, Luis (1996). Fundamentos del Derecho civil patrimonial, t. I, $3^{\text {a }}$ edición, Madrid: Civitas, p. 275 -no de una manera clara-; Medina Alcoz, M. (2005). "La ruptura injustificada de los tratos preliminares: notas acerca de la naturaleza de la responsabilidad precontractual", Revista de Derecho Privado, pp. 79-105; Pantaleón, Fernando (1984-6). "Comentario STS 19.06.1984", Cuadernos Civitas de Jurisprudencia Civil, p 1876; Puig Brutau, J. (1988). Fundamentos de Derecho Civil, $3^{\text {a }}$ edición, t. II, vol. 1, Barcelona: Bosch. Por último, también hay voces en favor de considerar la responsabilidad precontractual como una tercera categoría entre ambas, contractual y extracontractual, como un tercer género o categoría basada en el abuso de derecho como: García Rubio, M.P. (1991). La responsabilidad precontractual en el derecho español, Madrid: Civitas; o en el principio de la buena fe (arts.7 y 1.258 del Código Civil español); o como un concepto autónomo Alonso Pérez, M. (1971). "La responsabilidad precontractual”, Revista Critica de Derecho Inmobiliario, No 485, pp. 859-922; Loвato DE Blas, J.M. (1976). "Consideraciones sobre el concepto de tratos preliminares", Revista General de Legislación y Jurisprudencia, No 6, pp. 540-581; Manzanares, A. (1984). "La responsabilidad precontractual en la hipótesis de ruptura injustificada de las negociaciones preliminares", Anuario de Derecho Civil, año XXXVII, vol. 2, pp. 687-748, y Manzanares, A. (1985). "La naturaleza de la responsabilidad precontractual o culpa in contrahendo", Anuario de Derecho Civil, año XXXVIII, pp. 979-1009. Ver además los trabajos citados de Asúa González, C.I. / Hualde Sánchez, J.J. (2003). 
tiene una presencia más o menos notable, según los casos, en los tribunales.

Hay relevantes diferencias entre las posiciones favorables a considerar la culpa in contrahendo como perteneciente al campo del derecho de contratos en la medida en que el daño que se produce nace de una relación precontractual que puede considerarse ya como una unión social o bien considerar que responden al derecho cuasi delictual o de responsabilidad extracontractual, en la medida en que por definición se trata de situaciones en las que no hay aún contrato o bien considerarlo un tertium genus a la vista de la dificultad para encajarlo en una u otra categoría ${ }^{16}$.

Cada sistema aborda el tema de un modo diferente y las situaciones son contempladas desde distintos puntos de vista. Por lo tanto no sorprenden las frecuentes e intensas discrepancias doctrinales, principalmente allí donde no hay una regla legal específica sobre la responsabilidad precontractual. Añadamos a ello que el common law no ha desarrollado una doctrina como tal sobre la culpa in contrahendo y que tampoco alberga una regla general de buena $\mathrm{fe}^{17}$.

\section{2) El Borrador de Marco Común de ReFerencia europeo So- BRE LA RESPONSABILIDAD PRECONTRACTUAL}

El Marco común de referencia europeo es un proyecto académico, resultado de la investigación llevada a cabo por el Study Group on a European Civil Code (conocido como grupo Von Bar) y el Research Group on EC Private Law (llamado también Acquis Group). No debe ser equiparado con el Marco común de referencia que la Comisión Europea pretende llevar a cabo, pero sin duda es importante dado que proporciona un modelo para ello ${ }^{18}$. Se ha basado en parte sobre la versión revisada de los Principios del Derecho Europeo de Contratos (PECL) y contiene principios, definiciones y reglas modelos de derecho privado europeo ${ }^{19}$. En cuanto al

16 En palabras Zimmermann (1996) 245: “culpa in contrahendo cae de lleno dentro del área gris entre el derecho de contratos y el derecho de delitos y hay mucho que decir acerca de la propuesta de que no se acopla propiamente ni en uno ni en el otro, sino que más bien forma una parte integral de un tercer tipo de responsabilidad" (traducción propia).

17 VAn ERP, J.H.M. (2003) 73, acerca del principio de buena fe como un requisito general y no solo atañe a los contratos con consumidores.

18 Comisión Europea (2003). “A More Coherent European Contract Law: An Action Plan”. Bruselas, 12 de febrero, 68 final.

19 Ver la Resolución de 12 diciembre 2007 adoptada por el Parlamento Europeo sobre derecho de contratos europeo que da la bienvenida a la investigación para la elaboración de un borrador de Marco Común de Referencia; hace un llamamiento a la Comisión para involucrar al Parlamento en este proceso antes de que se den pasos procedimentales; invoca a la Comisión a seguir el trabajo de los investigadores así como el resultado de los talleres sobre dicho marco que ya han tenido lugar, urge a la Comisión a coordinar el trabajo sobre un marco común y decidir sobre el ámbito del Marco Común de Referencia final solo después 
contenido, cubre tanto contratos como otros actos jurídicos, obligaciones y derechos correspondientes, ciertos contratos específicos y obligaciones no contractuales ${ }^{20}$. Por lo que a nuestro tema se refiere, puede observarse el artículo II.-3:30121:

Artículo II.-3:301 (Contracts and other juridical acts): Negotiations contrary to good faith and fair dealing:

1) A person is free to negotiate and is not liable for failure to reach an agreement.

2) A person who is engaged in negotiations has a duty to negotiate in accordance with good faith and fair dealing. This duty may not be excluded or limited by contract.

3) A person who has negotiated or broken off negotiations contrary to good faith and fair dealing is liable for any loss caused to the other party to the negotiations.

4) It is contrary to good faith and fair dealing, in particular, for a person to enter into or continue negotiations with no real intention of reaching an agreement with the other party.

De acuerdo con este precepto, podemos afirmar lo siguiente:

$1^{\circ}$ Libertad para llevar a cabo negociaciones contractuales: Las partes no están obligadas a alcanzar un acuerdo. La libertad de negociación es uno de los principios generales del derecho comunitario europeo y de la economía de mercado más importantes ${ }^{22}$. En consecuencia, como afirmación general, ninguna responsabilidad surge en caso de que fracasen las negociaciones para alcanzar un contrato.

de una amplia discusión con todos los grupos interesados, investigadores e interesados. La Resolución reitera el fuerte apoyo para un acercamiento al asunto basado sobre un amplio Marco Común de Referencia sobre derecho general de contratos más allá del campo de la protección al consumidor. Ver también: Parlamento Europeo (2006). Resolución de 7 de septiembre sobre Derecho Europeo de Contratos (DOUE C 305 E 14.12.2006) y Comisión Europea (2007). Informe de 25 de julio "Second progress Report on the Common Frame of Reference (COM (2007) 0447 25.07.2007).

20 VAn Erp, J.H.M. (2003) 80. El Borrador de Marco Común fue presentado en la Conferencia: "The Draft Common Frame of Reference", que tuvo lugar en la ERA (Academia de Derecho Europeo, Trier, 6-7 de marzo de 2008).

21 No se ha publicado en el momento en el que se escribe este artículo ninguna traducción al castellano del mismo.

22 Acerca de la ruptura de negociaciones precontractuales en los diferentes sistemas, puede verse: Whittaker, S. / Zimmermann, R. (dirs.) (2000). Good faith in European Contract Law, Oxford: Cambridge University Press, pp. 236-256. Para un panorama general de Derecho europeo y de los países de Latinoamérica: ver Monsalve Caballero, V. (2008). La ruptura injustificada de los tratos preliminares, Tesis de grado, Universidad de Salamanca, España, y Schulze, R. (2006). "Deberes precontractuales y conclusión del contrato en el Derecho contractual europeo”, Anuario de Derecho Civil, tomo LIX, vol. 1, pp. 29-58. 
2o Las partes deben actuar con buena fe y conforme a una negociación justa (fair dealing) respecto a la formación de un contrato. La buena fe, como una regla ínsita en todos los sistemas legales de tipo continental o de raíz latina ha sido incluida en el borrador como un principio general ${ }^{23}$. Algo que es especialmente destacable y ha sido también subrayado por la doctrina europea ${ }^{24}$

$3^{\circ}$ Este principio no puede ser excluido o limitado (ius cogens)

$4^{\circ}$ La parte que rompe injustificadamente las negociaciones, habiendo creado una expectativa de que el contrato iba a celebrarse, debe responder. Es importante que la otra parte pudiera legítimamente esperar que el contrato fuera a perfeccionarse de acuerdo con el principio de la buena fe.

$5^{\circ}$ El precepto proporciona un ejemplo para dilucidar cuándo estamos ante un comportamiento contrario a la buena fe: "to enter into or continue negotiations with no real intention of reaching an agreement with the other party" (iniciar o continuar negociaciones sin intención de alcanzar ningún acuerdo con la otra parte). En este sentido la buena fe se convierte en un elemento presente desde el primer momento y se mantiene durante todo el periodo de negociaciones.

60 La parte responsable debe resarcir el daño ocasionado. El alcance de la compensación es el del interés negativo. El artículo utiliza el término "losses" (pérdidas) y bajo esta expresión se está aludiendo tanto al daño emergente como a la pérdida de oportunidad, si utilizamos como elemento interpretativo los Principios europeos del Derecho de contratos (ver infra), que como se ha dicho antes han constituido un elemento de referencia directo en la elaboración del borrador.

$7^{\text {o }}$ No aparece expresamente la exigencia de concurrencia de culpa.

$8^{\circ}$ La expresión latina culpa in contrahendo no aparece en el borrador y no hay ninguna referencia explícita al fundamento jurídico de la misma, esto es, no puede decirse que tenga un fundamento contractual o no contractual.

23 Hesselink, M. W. (2004). “The concept of good faith”, Towards a European Civil Code, he Hague: Kluwer Law, pp. 471 y ss.; Zahn, Y. / Machteld, J. / Rook, S. /Poissonnet, A.S. (2007). "Withdrawing from pre-contractual negotiations and the duty of good faith- harmonising European views", Ars Aequi, No 56, pp. 487-494.

24 A juicio de VAN Erp, J.H.M. (2003) 68-70, de un lado, la buena fe ha constituido un referente estándar de carácter externo que se ha aplicado a las relaciones contractuales, de otra parte, el deber de cuidado ha sido el criterio estándar para la responsabilidad extracontractual. Pues bien, ahora la buena fe no es vista ya solo como un estándar externo con relación al cumplimiento o exigibilidad de una obligación, sino como un criterio que gobierna toda la relación contractual en su conjunto. Las obligaciones que surgen de un contrato no nacen tanto del contrato en sí como de una relación contractual que se desarrolla en el tiempo. Su punto de partida es que el derecho de contratos se ha convertido en un derecho más flexible y es también la expresión de una visión más dinámica sobre el derecho de contratos. Además, daño extracontractual y contractual están experimentando a su juicio una convergencia gradual. 


\section{3) Los PRincipios europeos Del DeRECHO DE CONTRATOS Y OTROS PROYECTOS DE ARMONIZACIÓN CONTRACTUAL}

Si se compara el borrador del Marco Común de Referencia europeo con los Principios europeos de Derecho de contratos -documento elaborado por el grupo sobre Derecho europeo de contractos liderado por el profesor Lando sobre el cual aquel se ha basado en cierta medida- es fácil observar la proximidad entre ambos textos ${ }^{25}$. Los Principios establecen la buena fe y la negociación justa como deberes generales en el art. 1:201 $(1)^{26}$, aplicables ambos tanto al periodo precontractual como al contractual y específicamente contemplan la responsabilidad por negociaciones contrarias a la buena fe en el Artículo 2:301:

Articulo 2:301: Negociaciones contrarias a la buena fe

1) Las partes tienen libertad para negociar y no son responsables en caso de no llegar a un acuerdo.

2) Sin embargo, la parte que hubiere negociado o roto las negociaciones de manera contraria a las exigencias de la buena fe, será responsable de las pérdidas causadas a la otra parte.

3) En especial es contrario a la buena fe que una parte entable negociaciones o prosiga con ellas si no tiene intención alguna de llegar a un acuerdo con la otra parte ${ }^{27}$.

Se observa que el borrador del Marco común de referencia es más claro y más extenso que los Principios ${ }^{28}$; y en este sentido destaca especialmente la referencia a que la buena fe precontractual no pueda ser ni

25 Esta comisión tenía como objetivo básico elaborar principios comunes de derecho continental y common law. Véase Lando, O. I Beale, H. (eds.) (2003). Principles of European Contract Law, tomos I y II, The Hague: Kluwe Law Internacional; Lando, O. I Clive, E. I Prum, A. (eds.) (2003). Principles of European Contract Law. Tomo III, Nijhoff Dordrecht: Kluwer International. La última versión de este documento es del año 2005.

26 Artículo 1:201 (1) "Each party must act in accordance with good faith and fair dealing". Ver Whittaker, S. / Zimmermann, R. (dirs.) (2000); Kötz, K. (1998). "Towards a European Civil code: the duty of good faith”, en Cane, P. / Stapleton, J.: The Law of obligations. Essays in celebration of John Fleming, Oxford: Clarendon Presspp. 243-259; Schulze, R. I SchulTe-Nölke, H. (dirs.) (2002). European Contract Law in Comnunity Law, Köln: Bundesanzeiger, pp. 127 y ss.

27 Article 2:301: Negotiations Contrary to Good Faith:

(1) A party is free to negotiate and is not liable for failure to reach an agreement.

(2) However, a party who has negotiated or broken off negotiations contrary to good faith and fair dealing is liable for the losses caused to the other party.

(3) It is contrary to good faith and fair dealing, in particular, for a party to enter into or continue negotiations with no real intention of reaching an agreement with the other party.

Ver traducción al español con comentarios de estos PECL: Díez-Picazo, L. / Roca-Trias, E. / Morales Moreno, A. (2002). Los principios del derecho europeo de contratos, Madrid: Civitas.

28 Von Bar et alii (2008) 38. 
excluida ni limitada por contrato ("may not be excluded or limited by contract").

Además, este artículo encuentra una gran similitud con la referencia a las negociaciones precontractuales que aparece en los Principios UNIDROIT (Principios de los Contratos comerciales internacionales), cuya primera edición vio la luz en 1994 y la segunda en el año $2004^{29}$.

En este sentido, la buena fe y el fair dealing también obligan a las partes en esta suerte de código internacional ${ }^{30}$ y se regula lo que estos principios llaman "negotiations in bad faith" (Artículo 2.1.15). Llama la atención la utilización de la expresión negativa "bad faith" (mala fe), en lugar de "good faith" (buena fe).

\section{Artículo 2.1.15: (Negociaciones de mala fe)}

1) Las partes tienen plena libertad para negociar los términos de un contrato y no son responsables por el fracaso en alcanzar un acuerdo.

2) Sin embargo, la parte que negocia o interrumpe las negociaciones de mala fe es responsable por los daños y perjuicios causados a la otra parte.

3) En particular, se considera mala fe que una parte entre en o continúe negociaciones cuando al mismo tiempo tiene la intención de no llegar a un acuerdo ${ }^{31}$.

Además de los PECL, se han llevado a cabo otros proyectos europeos de unificación contractual ${ }^{32}$ y entre ellos destaca el código europeo de contratos elaborado por la Accademia dei Giusprivatisti Europei (Pavia, Italia) bajo el liderazgo del profesor Gandolfi, ${ }^{33}$ que incluye también una sección dedicada a los llamados en este texto Tractations précontractuelles

29 Ver Instituto Internacional para la Unificación del Derecho Privado: website: htpp://www. unidroit.org, para más información sobre el propósito de esta organización intergubernamental. Bonell, M.J. (1999). A new Approach to International Commercial Contracts. The UNIDROIT Principles of International Commercial Contracts, The Hague-London-Boston: Kluwer Law International; Lando, O. (2005). "CISG and its Followers: A Proposal to Adopt Some International Principles of Contract Law", American Journal of Comparative Law, pp. 379-401.

30 Artículo 1.7: (1) Good faith and fair dealing: "Each party must act in accordance with good faith and fair dealing in international trade". Ver: Kramer, E.A. (1997). "Fair dealing in International Trade et vices du consentement", en Bonell, M.J. / Bonelli, F.(eds.): Contratti commerciali internazionali e Principi UNIDROIT, Milano: Giuffrè, pp. 161-169.

31 htpp://www.unidroit.org. Ver versión oficial en español.

32 Ninguno de ellos ha entrado en vigor, ello sin perjuicio del apoyo prestado por las instituciones comunitarias. Véase Comisión Europea (2001). Comunicación de 11 de julio de 2001, Official Journal de 15 de noviembre de 2001.

33 http://www.accademiagiusprivatistieuropei.it. En este caso el objetivo fue el de elaborar un código y no unos principios, bajo la inspiración del Código Civil italiano y el Código de Contratos de Harvey McGregor. Las lenguas de trabajo fueron en este caso el francés y el italiano. La versión original fue escrita en francés. 
(Tratos precontractuales) ${ }^{34}$. El artículo 6 específicamente trata este aspecto bajo el título de "devoir de correction" y lo hace en términos próximos a los arriba mencionados de los PECL y los UNIDROIT:

Art. 6. Deber de protección.

1. Cada parte es libre de iniciar tratos preliminares con el fin de celebrar un contrato, sin que se le pueda imputar ninguna responsabilidad en el caso de que aquel no se perfeccione, salvo si su comportamiento es contrario a la buena fe.

2. Actúa contra la buena fe la parte que inicia o prosigue tratos preliminares sin intención de llegar a la celebración del contrato.

3. Si en el transcurso de los tratos preliminares las partes han examinado ya los elementos esenciales del contrato, cuyo eventual perfeccionamiento se prevé, la parte que ha suscitado en la otra una confianza razonable en cuanto a la celebración del mismo, actúa contra la buena fe desde que interrumpe los tratos preliminares sin motivo justificado.

4. En los casos previstos en los párrafos anteriores, la parte que ha actuado contra la buena fe está obligada a reparar el daño sufrido por la otra hasta el máximo de los gastos comprometidos por esta última en el curso de los tratos preliminares con vistas a la celebración del contrato, asi como por la pérdida de ocasiones similares causada por los tratos pendientes ${ }^{35}$.

En suma, de todos los textos arriba mencionados pueden extraerse las siguientes ideas comunes:

$1^{\text {o }}$ Todos ellos contienen una regulación de la responsabilidad en que se puede incurrir en el periodo precontractual. Aun con diversos matices reflejan la voluntad evidente de que ese espacio de encuentro

34 El proyecto también regula los deberes de información (art. 7); revelación de información (art. 8); deberes en los contratos con consumidores y la buena fe (art. 9), así como los tratos precontractuales en los contratos internacionales.

35 Article. 6: Devoir de correction

1. Chacune des parties est libre d'entreprendre des tractations en vue de conclure un contrat sans qu'on puisse lui imputer la moindre responsabilité au cas où le contrat ne serait pas stipulé, sauf si son comportement est contraire à la bonne foi.

2. Agit à l'encontre de la bonne foi la partie qui entreprend ou poursuit les tractations sans l'intention de parvenir à la conclusion du contrat.

3. Si au cours des tractations les parties ont déjà examiné les éléments essentiels du contrat, dont on prévoit l'éventuelle conclusion, celle des parties qui a suscité auprès de l'autre une confiance raisonnable quant à la stipulation du contrat, agit à l'encontre de la bonne foi dès lors qu'elle interrompt les tractations sans motif justifié.

4. Dans les cas prévus aux alinéas précédents, la partie qui a agi à l'encontre de la bonne foi est tenue de réparer le dommage subi par l'autre partie au maximum dans la mesure des frais engagés par cette dernière au cours des tractations en vue de la stipulation du contrat, ainsi que de la perte d'occasions similaires causée par les tractations pendantes. 
negocial esté regulado. Y ello es un paso adelante respecto al silencio del Convenio de Viena (1980) que no alude al mismo ${ }^{36}$.

$2^{\circ} \quad$ Ninguno de estos textos utiliza la expresión latina culpa in contrahendo. Podría plantearse como hipótesis una renuncia explícita por parte de los académicos que han elaborado estos documentos en orden a lograr un resultado de armonización lo más amplio posible al que puedan adherirse tanto los sistemas de common law como de civil law.

$3^{\circ}$ Los preceptos citados no regulan la responsabilidad precontractual como un todo, sino las situaciones ligadas a la ruptura de la buena fe en el periodo de negociación contractual. Quedan en la sombra los casos en los que se produce una nulidad contractual debido a dolo o fraude de una parte sobre la otra, sin perjuicio de que pudieran tener cabida dentro de la ruptura del principio de buena fe que se proyecta con carácter general en el estadio o fase precontractual.

$4^{\circ}$ No contienen ninguna referencia explícita al fundamento de esta responsabilidad.

\section{4) CULPA IN CONTRAHENDO EN EL REGLAMENTO EUROPEO SOBRE OBLIGACIONES NO CONTRACTUALES (ROMA II)}

Se han publicado en la Unión Europea en los últimos tiempos dos Reglamentos relativos a la ley aplicable a las obligaciones contractuales y no contractuales. Se trata del Reglamento (EC) No 864/20007, del Parlamento Europeo y del Consejo sobre la ley aplicable a las obligaciones no contractuales, de 11 de julio de 2007 (Roma II) ${ }^{37}$, y el Reglamento (EC) 503/2008 del Parlamento Europeo y del Consejo sobre ley aplicable a las obligaciones contractuales, de 4 de julio de 2008 (Roma I) ${ }^{38}$. Ambos Reglamentos se enmarcan en la sección de "Libertad, seguridad y justicia” de la Unión Europea y el primero de los cuales regula la culpa in contrahendo.

36 Naciones Unidas (1980). Convención sobre contratos de venta internacional de mercaderias. Disponible en http://www.uncitral.org/uncitral/es/uncitral_texts/sale_goods/1980CISG. html. Esta convención comercial fue firmada el 11 de abril de 1980, es todavía la base de la lex mercatoria y constituye el primero y uno de los más importantes instrumentos legales en el proceso de unificación jurídica entre los principios de common law y continental law.

37 Se aplica desde el 11 de enero de 2009, excepto el art. 29, que entró en vigor el 11 de julio de 2008 (art. 32).

38 DOUE L177/6, 4 julio 2008. Entra en vigor el 17 de diciembre de 2009, excepto el Art. 26 que entró en vigor el 17 de junio de 2009 (art. 29). 


\section{1) CULPA IN CONTRAHENDO EN EL REGLAMENTO ROMA II: EXPRE- SIÓN Y SITUACIONES INCLUIDAS}

El Reglamento europeo conocido como Roma II tiene por objeto establecer un sistema de reglas aplicables a las obligaciones extracontractuales en materia civil y mercantil no contractuales, esto es, las obligaciones civiles extracontractuales y las que derivan de la comisión de un delito, con las excepciones que establece el propio reglamento. A lo que se añade también el enriquecimiento injusto, la gestión de negocios ajenos y la culpa in contrahendo ${ }^{39}$.

Esto incluye expresamente una regulación para esta última, que curiosamente no estaba en el proyecto original. El artículo se introdujo en la Propuesta presentada por la Comisión europea a causa precisamente de las profundas diferencias existentes entre los distintos sistemas legales europeos sobre las diversas situaciones que pueden conocerse como culpa in contrahendo así como su cualificación como responsabilidad contractual y no contractual. Decía esta expresamente que: "la línea de demarcación entre las obligaciones contractuales y las basadas en los delitos o responsabilidad extracontractual no es idéntica en todos los Estados miembros y puede haber dudas sobre si debería aplicarse el Convenio de Roma o la propuesta de Reglamento por ejemplo en el caso de responsabilidad precontractual o culpa in contrahendo" 40 .

Por lo tanto, era importante incorporar una regla específica para la culpa in contrahendo en caso de litigación en el mercado europeo, lo que resulta ser el artículo 12 .

Artículo 12: Culpa in contrahendo.

1. La ley aplicable a una obligación extracontractual que se derive de los tratos previos a la celebración de un contrato, con independencia de que el contrato llegue o no a celebrarse realmente, será la ley aplicable al contrato o la que se habría aplicado al contrato si este se hubiera celebrado ${ }^{41}$. 2. Cuando la ley aplicable no pueda determinarse mediante el apartado 1, la ley aplicable será:

\footnotetext{
39 Según el artículo 2.1: "a los efectos del presente Reglamento, se entenderá por "daños" todas las consecuencias resultantes de un hecho dañoso, el enriquecimiento injusto, la gestión de negocios o la culpa in contrahendo. El Consejo europeo celebrado el 5 de noviembre de 2004 hizo un llamamiento para trabajar activamente en orden a lograr unas reglas de conflicto relativas a obligaciones no contractuales intentando dar una respuesta al mercado europeo que requiere unos elementos de litigación predecible y de seguridad en cuanto a la ley aplicable.

40 Propuesta presentada por la Comisión Europea. Comisión Europea (2003). Comunicación de 22 de julio, 2003/0168, 427 final, art. (11). Traducción propia.

41 Ver infra el Reglamento Roma I.
} 
a) la ley del pais en el que se haya producido el daño, independientemente del pais en el que se haya producido el hecho generador del daño $e$ independientemente del pais o paises en los que se hayan producido las consecuencias indirectas del hecho en cuestión, $o$

b) cuando las partes tengan su residencia habitual en el mismo pais en el momento en el que se produjo el hecho generador del daño, la ley de ese pais, $o$

c) si del conjunto de las circunstancias se desprende que la obligación extracontractual que se derive de los tratos previos a la celebración de un contrato presenta vinculos manifiestamente más estrechos con otro pais distinto del indicado en las letras a) y b), se aplicará la ley de este otro país.

Para una definición de las situaciones que pudieran incluirse en esta expresión -en cuanto concierne al Reglamento- ha de verse el parágrafo 30:

Parágrafo 30:

La culpa in contrahendo a efectos del presente Reglamento es un concepto autónomo y no debe interpretarse necesariamente dentro del sentido de la legislación nacional.

Debe incluir la violación del deber de información y la ruptura de los tratos contractuales. El articulo 12 cubre únicamente las obligaciones extracontractuales con vinculo directo con los tratos previos a la celebración de un contrato. Esto quiere decir que si durante las negociaciones de un contrato una persona sufriera una lesión personal, se aplicaría el articulo 4 o cualquier otra disposición pertinente del Reglamento.

La apreciación más inmediata que cabe hacer es la de la utilización por el Reglamento europeo de la expresión "culpa in contrahendo". Es la primera vez que aparece en un Reglamento europeo sobre reglas de conflicto para obligaciones no contractuales. Sin embargo, se debe subrayar el curioso dato de que cuatro de las versiones a lenguas comunitarias no utilizan la expresión latina.

Eso acontece en la versión holandesa del Reglamento que utiliza la expresión "precontractuele aansprakelijkheid -reponsabilidad precontractual"-, la versión alemana que emplea la de "Verschulden bei Vertragsverhandlungen - responsabilidad en caso de negociaciones contractuales-, la checa ("predsmluvni odpovědnost") y la eslovaca ("predzmluvná zodpovednost" $)^{42}$. Estas cuatro versiones han eludido la expresión culpa in

42 Por el contrario, la expresión culpa in contrahendo sí aparece en las siguientes versiones: inglesa, francesa, portuguesa, espańola, italiana, búlgara, danesa, polaca, estonia, irlandesa, letona, húngara, maltesa, rumana y eslovena. Otras versiones nacionales usan tanto la expresión latina como la traducción a su propia lengua, como acontece con la versión griega:

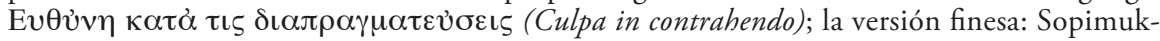


contrahendo que abarca situaciones que el Reglamento como tal no aborda. En estos casos la propia lengua garantiza una idea más precisa de las situaciones que realmente están incluidas en la norma.

En segundo lugar, por lo que se refiere al objetivo de esta expresión, el parágrafo 30 afirma que "la culpa in contrahendo a efectos del presente Reglamento es un concepto autónomo y no debe interpretarse necesariamente dentro del sentido de la legislación nacional". Esto es, que las situaciones reguladas en el artículo 12 son solo obligaciones no contractuales que surgen de negociaciones previas a la conclusión del contrato (con independencia de que el contrato se haya concluido o no), el cual incluye la "violación del deber de confidencialidad y la ruptura de negociaciones contractuales (parágrafo 30). Por lo tanto, este artículo no pretende integrar todas las posibles situaciones comprendidas en la así denominada culpa in contrabendo, y tampoco en la responsabilidad precontractual. Este parágrafo lo que afirma es que "el artículo 12 cubre únicamente las obligaciones extracontractuales con vinculo directo con los tratos previos a la celebración de un contrato. Esto quiere decir que si durante las negociaciones de un contrato una persona sufriera una lesión personal, se aplicaria el articulo 4 o cualquier otra disposición pertinente del Reglamento". Esta última referencia a los daños personales es una alusión directa a las situaciones que en el derecho alemán tienen cabida dentro de la responsabilidad precontractual desde el emblemático caso conocido como "Linoleum Fall”, que de esta manera explícita quedan fuera del ámbito de culpa in contrahendo, de acuerdo con el Reglamento comunitario.

\section{2) FUNDAMENTO DE LA CULPA IN CONTRAHENDO EN ROMA II}

La culpa in contrahendo aparece en el Reglamento Roma II en el marco de las reglas aplicables a las obligaciones no contractuales, como se ha visto, mientras que las relativas al derecho aplicable a las obligaciones contractuales fueron reguladas un año más tarde en el Reglamento Roma I, de 17 de junio de $2008^{43}$. Este último Reglamento excluye de su ámbito de forma expresa las "las obligaciones que se derivan de los tratos

sentekotuottamus (Culpa in contrahendo) y la versión sueca: Sopimuksentekotuottamus (Culpa in contrahendo).

43 Parlamento Europeo (2007). Reglamento No 864/2007 y Consejo Europeo (2008). Reglamento de 17 de junio, sobre la ley aplicable a las obligaciones contractuales (Roma I). Este Reglamento sustituye al Convenio de Roma de 1980 (DOUE, L 266, 9 de octubre 1980), que era el único instrumento de derecho privado internacional en el ámbito comunitario que quedaba bajo la forma de tratado internacional. Ello explica el interés en convertirlo en regulación europea. Véase en ese sentido el "Green Paper acerca de la conversión del Convenio de Roma de 1980 sobre la ley aplicable a las obligaciones contractuales dentro de un instrumento comunitario europeo y su modernización (presentado por la Comisión europea, en Bruselas, el 14 de enero de 2003. COM (2002) 654 final). 
previos a la celebración de un contrato” (artículo 1.2 i) ${ }^{44}$ y no utiliza la expresión culpa in contrahendo, a diferencia del Reglamento Roma II, que incluso encabeza la regulación bajo este título ${ }^{45}$.

La Propuesta de Reglamento presentada por la Comisión explicaba las razones para excluirla del Reglamento relativo a las obligaciones contractuales. Decía que según el análisis de la mayoría de los sistemas jurídicos de la Unión, así como la concepción restrictiva del contrato adoptada por el Tribunal de Justicia en su jurisprudencia sobre el apartado 1 del artículo 5 del Reglamento "Bruselas I": para las necesidades de Derecho internacional privado, estas se calificarían de delictuales y se regirían por el futuro instrumento "Roma II" 46.

Pero a pesar de la inclusión de la culpa in contrahendo en el ámbito regulatorio del Reglamento Roma II, el régimen que se le aplica no es el general para las obligaciones no contractuales o delictuales, en las que se aplica la ley donde el daño ha ocurrido (principio lex loci delicti commissi). De acuerdo con el artículo 12, para la culpa in contrahendo, como se ha visto anteriormente "será la ley aplicable al contrato o la que se habría aplicado al contrato si este se hubiera celebrado". Es decir, que a pesar de la inclusión expresa de la culpa in contrahendo en el marco de las obligaciones no contractuales, al menos en cuanto a reglas de conflicto se refiere, lo cierto es que el único derecho aplicable es la ley del contrato o la ley que habría sido aplicable si el contrato se hubiera celebrado. Allí donde no es posible determinar tal derecho, el parágrafo segundo da las conexiones generales de este Reglamento. En opinión de algunos autores, esta regla parece contener una solución lógica porque la ley del contrato puede ser más fácil de conocer y además porque los conflictos que surgen en las negociaciones preliminares están usualmente ligados a conflictos sobre el contrato mismo. No obstante, desde otro punto de vista, esta solución no es totalmente apropiada desde el momento en que la ley de un futuro contrato puede regir la obligación específica de no romper injustificadamente la negociación y las partes no pueden depender de la ley del país en el que cualquiera de ellos tenga su residencia habitual para sostener la posibilidad de romper las negociaciones sin resultar responsable de ello ${ }^{47}$.

$44 \quad$ El parágrafo (10) del Reglamento explica que "las obligaciones que se derivan de los tratos previos a la celebración de un contrato están reguladas por el artículo 12 del Reglamento (CE) No 864/2007. Cuestión que no era mencionada en el Convenio de Roma de 1980.

45 La propuesta previa de este Reglamento (ver supra) fue escrita en términos distintos: "obligations arising out of a pre-contractual relationship" (obligaciones que surgen de una relación precontractual).

46 Ver la Propuesta presentada por la Comisión Europea, en Bruselas, el 15 de diciembre de 2005. COM (2005) 650 final. 2005/0261 (COD).

47 Garcimartin Alférez, F.J. (2007). "La unificación del Derecho conflictual en Europa: El Reglamento sobre ley aplicable a las obligaciones extracontractuales (Roma II), Diario La Ley, No 6811, de 31 de octubre, y Garcimartin Alférez, F.J. (2008). "El Reglamen- 
No es la culpa in contrahendo la única excepción, sino que hay otras dos: el enriquecimiento injustificado y la negotiorum gestio ${ }^{48}$, clasificables en la tradicional categoría de los cuasicontratos.

Además, esta regulación contrasta con una decisión judicial del Tribunal europeo de Luxemburgo sobre un caso de ruptura de tratos preliminares que motivó el planteamiento de una cuestión prejudicial en orden a cuál era el tribunal competente para conocer de la responsabilidad derivada de los daños ocasionados por la conducta de una de las partes en el curso de una negociación precontractual. Se trata de la sentencia de 17 de septiembre de 2002 (Caso C-334/00, Fonderie Officine Meccaniche Tacconi Spa vs. Heinrich Wagner Sinto Maschinenfabrik GmbH) ${ }^{49}$. Un buen ejemplo del hecho de las soluciones legales en este tipo de asuntos varían ampliamente de un país a otro y que requerían una norma de conflicto al efecto. Cuando se dictó la sentencia no estaba el Reglamento Roma II aprobado y ambas partes discutían sobre el tribunal competente para resolver el caso (Alemania o Italia)..$^{50}$

Se trataba de encontrar la interpretación del artículo 5(1) y del artículo 5 (3) del Convenio de Bruselas, de 27 de julio de 1968, sobre la competencia judicial y la ejecución de resoluciones judiciales en materia civil y mercantil ${ }^{51}$ en orden a determinar qué tribunal tenía jurisdicción para entender del caso. El Convenio no establece reglas para los supuestos de responsabilidad precontractual. De un lado, el artículo 5(1) afirma que los tribunales del lugar del cumplimiento de la obligación tienen jurisdicción en asuntos relacionados con el contrato. De otro, el artículo 5(3) en supuestos relacionados con delitos, cuasidelitos y daños extracontractuales, es competente el tribunal del lugar donde se ha producido el daño ${ }^{52}$.

to "Roma I" sobre ley aplicable a las obligaciones contractuales: ¿cuánto ha cambiado el Convenio de Roma de 1980", Diario La Ley, No 6957, de 30 de mayo; Arenas García, R. (2008). "La regulación de la responsabilidad precontractual en el Reglamento Roma II", Indret (www.indret.com), octubre, pp. 1-27.

48 Bruselas, 22 de julio de 2003. COM (2003) 427 final. 2003/0168 (COD).

49 DOUE C 274/11, 9 de noviembre de 2002.

50 También puede ser mencionado otro caso en relación a la responsabilidad por actos producidos con anterioridad al contrato, en concreto para la reclamación de un premio a favor de un consumidor: ECJ, 11 de junio de 2002, C-96/00, Caso Rudolf Gabriell.

51 En su versión modificada por el Convenio de 9 de octubre de 1978 relativo a la adhesión del Reino de Dinamarca, de Irlanda y del Reino Unido de Gran Bretańa e Irlanda del Norte, por el Convenio de 25 de octubre de 1982 relativo a la adhesión de la República Helénica y por el Convenio de 26 de mayo de 1989 relativo a la adhesión del Reino de España y de la República Portuguesa.

52 Resulta de interés la opinión del abogado general Geelhoed (31 de enero de 2002): http:// curia.europa.eu/en/content/juris/index.htm: "El Convenio no establece ninguna regla sobre responsabilidad derivada de relaciones precontractuales per se. La indicación más clara puede encontrarse en el Informe Evrigenis (DOUE 1986 C 298). Este informe proporciona información sobre el Convenio con ocasión de la incorporación de Grecia. El informe afirma que las relaciones precontractuales pueden caer dentro el ámbito del art. 5 (1). Sin embargo, el informe no establece el fundamento sobre el cual se basa esta opinión" (Traducción propia). 
La discusión versaba sobre cómo debe clasificarse exactamente la ruptura de negociaciones preliminares, si como responsabilidad contractual o como responsabilidad precontractual.

De una parte, la empresa italiana acusaba a la compañía alemana de una negativa a perfeccionar el contrato de compraventa de forma injustificada y como consecuencia de tal ruptura la de su deber de actuar honestamente y de conformidad con la buena fe. Por su parte la empresa alemana alegaba que ningún acuerdo se había alcanzado entre ambas empresas porque sus propuestas habían ya recibido contrapropuestas. Así las cosas, por lo tanto, la responsabilidad precontractual de la compañía alemana se fundamentó en el artículo 1.337 del Código Civil italiano y por ello según el artículo 5(3) del Convenio de Bruselas era competente la jurisdicción italiana por ser el lugar donde el hecho dañoso sucedió, lo que debe ser también comprendido como el lugar donde la parte demandante ha sido dañada, ha sufrido una pérdida (en concreto, en Perugia, que es donde la empresa italiana tiene su sede). La compañía alemana por contra considera que los tribunales italianos carecían de competencia para resolver sobre el tema, que encajaba propiamente en el art. $5(1)^{53}$.

Las conclusiones del tribunal fueron que "en circunstancias como las del asunto principal, caracterizado por la inexistencia de compromisos libremente asumidos por una parte frente a otra con ocasión de las negociaciones encaminadas a la celebración de un contrato y por la eventual infracción de normas jurídicas, en particular la que obliga a las partes a actuar de buena fe en dichas negociaciones, la acción mediante la cual se invoca la responsabilidad precontractual del demandado está comprendida en la materia delictual o cuasidelictual, en el sentido del artículo 5, número 3, del Convenio de 27 de septiembre de 1968".

Parece en este sentido que el Reglamento Roma II ha seguido aparentemente esta regla porque la culpa in contrahendo (al menos por lo que se refiere al resarcimiento de los daños que puedan surgir de la ruptura injustificada de las negociaciones) ha sido incluida dentro del marco de

53 Los hechos en detalle son los siguientes: El 23 de enero de 1996, Tacconi demandó a HWS ante el Tribunal de Perugia con el fin de que se declarara que HWS y la sociedad de arrendamiento financiero B.N. Commercio e Finanza SpA (en lo sucesivo, BN) no habían celebrado un contrato de venta de una fundidora automática, siendo así que BN y Tacconi ya habían celebrado, con el consentimiento de HWS, un contrato de arrendamiento financiero que tenía por objeto la citada fundidora automática. Según Tacconi, no se había celebrado el contrato entre HWS y BN debido a la negativa injustificada de HWS a proceder a la venta $y$, por consiguiente, debido al incumplimiento por la citada sociedad de las obligaciones de lealtad y buena fe que debe observar. De esta forma, HWS defraudó la confianza legítima de Tacconi, que había contado con que se celebrara el contrato de venta. Por lo tanto, Tacconi solicitaba que se condenara a HWS a reparar todos los perjuicios que supuestamente le había irrogado, perjuicios cuyo importe evaluaba en 3.000 millones de liras italianas. 
las obligaciones no contractuales. Pero la ley aplicable será la ley del contrato (artículo 12) y no la ley donde el hecho dañoso se haya producido.

\section{CONCLUSIONES}

De lo dicho hasta aquí se pueden extraer algunas conclusiones:

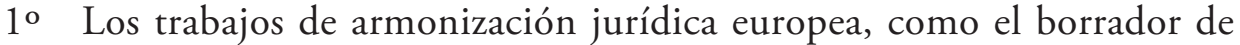
Marco común de referencia o los Principios europeos de Derecho de contratos establecen la libertad para contractar y el principio de buena fe en la fase de negociaciones preliminares, así como las consecuencias de las actuaciones contrarias a las mismas, con más o menos amplitud y detalle.

No obstante, ninguno de estos recientes proyectos académicos utilizan la expresión culpa in contrahendo ni clarifican el fundamento de la responsabilidad que generan (contractual o no contractual).

$2^{\circ}$ El Reglamento europeo sobre la ley aplicable a las obligaciones no contractuales (Roma II) ha incluido entre ellas a la culpa in contrahendo, usando precisamente esta expresión (si bien es cierto que algunas de las versiones nacionales, como la alemana y la holandesa eluden la expresión latina). Ello a la vista del análisis de la mayor parte de los ordenamientos europeos que la califican de responsabilidad no contractual, no obstante el Reglamento europeo la considera como un concepto autónomo en el derecho europeo, dado que las instituciones comunitarias son conscientes de la divergencia en este tema.

La norma europea se refiere con esa expresión solamente a los tratos previos a la conclusión del contrato, que incluye la infracción del deber de confidencialidad y la ruptura injustificada de las negociaciones preliminares, por lo tanto con una óptica más restringida de lo que se ha incluido por unos u otros ordenamientos en aquella clásica expresión ${ }^{54}$.

$3^{\circ}$ La regla que establece el Reglamento Roma II no es el que está previsto para el derecho de los delitos, cuasidelitos y daños extracontractuales. La culpa in contrahendo constituye una excepción legal dado que la norma que será aplicable es la ley del contrato (o la que hubiera sido aplicable en el caso de que el contrato hubiera llegado a concluirse). No debe por ello extraerse una conclusión de este criterio en orden a afirmar si ello constituye una afirmación sobre el fundamento contractual o no contractual de este tipo de responsabilidad. Las reglas de conflicto no ofrecen una base para ello, dado que 
la referencia a la ley del contrato puede tener como fundamento razones prácticas sin que pueda afirmarse que con ello se está haciendo un pronunciamiento sobre la naturaleza de la culpa in contrahendo.

\section{BIBLIOGRAFÍA}

- Almeida Costa, M.J.B. (1999). Direito das Obrigaçoes, Coimbra: Almedina.

- Alonso Pérez, M. (1971). "La responsabilidad precontractual", Revista Critica de Derecho Inmobiliario, No 485, pp. 859-922.

- Arenas García, R. (2008). "La regulación de la responsabilidad precontractual en el Reglamento Roma II", Indret (www.indret.com), octubre, pp. 1-27.

- Asúa González, C.I. (1989). La culpa in contrahendo (Tratamiento en el Derecho alemán y presencia en otros ordenamientos), Bilbao: Ediciones Universidad del País Vasco.

- Asúa González, C.I. / Hualde Sánchez, J.J. (2003). "Codificación de la culpa in contrahendo en el Derecho alemán”, en VV. AA.: Estudios en Homenaje al Profesor Luis Diez-Picazo, vol. II, Madrid: Civitas, pp. 1415-1433.

- Bonell, M.J. (1999). A new Approach to International Commercial Contracts. The UNIDROIT Principles of International Commercial Contracts, The Hague-London-Boston: Kluwer Law International.

- Cabanillas Sánchez, A. (1995). "El ámbito de la responsabilidad precontractual o la culpa in contrahendo", Revista Critica de Derecho Inmobiliario, pp. 747-788.

- Carrasco Perera, A. (2006). "Cartas de intenciones, precontratos, responsabilidad in contrahendo y obligatoriedad de los tratos en la jurisprudencia española”, Aranzadi Civil, No 21, pp. 15-38.

- Cartwright, J. / Hesselink, M. (ed.) (2009). Precontractual liability in European private law, Oxford: Cambridge University Press.

- Caruso, D. (1993). La culpa in contrahendo. L'esperienza statunitense e quella italiana, Milano: Giuffrè.

- Coherier, C. (1939). Des obligations qui naissent des pourparlers préables a la formation des contrats, Paris: Publications Paris.

- Comisión Europea (2007). Informe de 25 de julio "Second progress Report on the Common Frame of Reference (COM (2007) 0447 25.07.2007).

- Comisión Europea (2003). Comunicación de 22 de julio, 2003/0168, 427 final, art. (11).

\footnotetext{
- (2003). "A More Coherent European Contract Law: An Action Plan". Bruselas, 12 de febrero, 68 final.

- (2001). Comunicación de 11 de julio de 2001, Official Journal de 15 de noviembre de 2001.
} 
- De los Mozos, J.L (2005). "Responsabilidad en los tratos preparatorios del contrato", en VV. AA: Estudios sobre Derecho de contratos, integración europea y codificación, Madrid: Dykinson.

- Di Donna, L. (2008). Obblighi informativi precontrattuale, vol. I (la tutela del consumitore), Milano: Giuffrè. Díez-Picazo, Luis (1996). Fundamentos del Derecho civil patrimonial, t. I, $3^{\text {a }}$ edición, Madrid: Civitas.

- Díez-Picazo, L. / Roca-Trias, E. / Morales Moreno, A. (2002). Los principios del derecho europeo de contratos, Madrid: Civitas.

- D’ors, Alvaro et alii (1968-1976). El Digesto de Justiniano, vol I, Pamplona: Aranzadi.

- Fagella, G. (1909). "Fundamento giuridico della responsabilitá in tema di trattative contrattuali", Archivio Giuridico "F. Serafini”.

- García Rubio, M.P. (1991). La responsabilidad precontractual en el derecho español, Madrid: Civitas.

- Garcimartin Alférez, F.J. (2007). "La unificación del Derecho conflictual en Europa: El Reglamento sobre ley aplicable a las obligaciones extracontractuales (Roma II), Diario La Ley, No 6811, de 31 de octubre.

(2008). "El Reglamento "Roma I" sobre ley aplicable a las obligaciones contractuales: ¡cuánto ha cambiado el Convenio de Roma de 1980", Diario La Ley, No 6957, de 30 de mayo.

- Hesselink, M. W. (2004). "The concept of good faith", Towards a European Civil Code, he Hague: Kluwer Law, pp. 471 y ss.

- Hilsenrad, A. (1934). Las obligaciones precontractuales, trad. de Menéndez Pidal, Madrid: Góngora.

- Hondius, Ewoud (1991). Precontractual liability, Deventer: Kluwer Law International.

- Kramer, E.A. (1997). "Fair dealing in International Trade et vices du consentement", en Bonell, M.J. / Bonelli, F. (eds.): Contratti commerciali internazionali e Principi UNIDROIT, Milano: Giuffrè, pp. 161-169.

- Lando, O. (2005). "CISG and its Followers: A Proposal to Adopt Some International Principles of Contract Law", American Journal of Comparative Law, pp. 379-401.

- Lando, O. / Beale, H. (eds.) (2003). Principles of European Contract Law, tomos I y II, The Hague: Kluwe Law Internacional.

- Lando, O. / Clive, E. / Prum, A. (eds.) (2003). Principles of European Contract Law. Tomo III, Nijhoff Dordrecht: Kluwer International.

- Lobato De Blas, J.M. (1976). "Consideraciones sobre el concepto de tratos preliminares", Revista General de Legislación y Jurisprudencia, No 6, pp. 540-581

- Manzanares, A. (1984). "La responsabilidad precontractual en la hipótesis de ruptura injustificada de las negociaciones preliminares", Anuario de Derecho Civil, año XXXVII, vol. 2, pp. 687-748. 
(1985). "La naturaleza de la responsabilidad precontractual o culpa in contrahendo", Anuario de Derecho Civil, ańo XXXVIII, pp. 979-1009.

- Medicus, D. (1986). "Zur Entdeckungsgeschichte der culpa in contrahendo", Fest. M. Kaser zum 80, Wien-Koln-Graz: Geburstag, pp. 169-180.

- Medina Alcoz, M. (2005). "La ruptura injustificada de los tratos preliminares: notas acerca de la naturaleza de la responsabilidad precontractual", Revista de Derecho Privado, pp. 79-105.

- Monsalve Caballero, V. (2008). La ruptura injustificada de los tratos preliminares, Tesis de grado, Universidad de Salamanca, España

- Naciones Unidas (1980). Convención sobre contratos de venta internacional de mercaderías. Disponible en http://www.uncitral.org/uncitral/es/uncitral_texts/sale_goods/1980CISG.html

- Pantaleón, Fernando (1984-6). "Comentario STS 19.06.1984", Cuadernos Civitas de Jurisprudencia Civil.

- Parlamento Europeo (2007). Reglamento No 864/2007 y Consejo Europeo (2008). Reglamento de 17 de junio, sobre la ley aplicable a las obligaciones contractuales (Roma I).

- (2006). Resolución de 7 de septiembre sobre Derecho europeo de Contratos (DOUE C 305 E 14.12.2006)

- Piotet, P. (1963). Culpa in contrahendo et Responsabilité précontractuelle en Droit privé suisse, Berna: ed. Staempli \& CIE, pp. 24 - 26.

- Puig Brutau, J. (1988). Fundamentos de Derecho Civil, $3^{\text {a }}$ edición, t. II, vol. 1, Barcelona: Bosch.

- Saleilles, R. (1907). "De la responsabilité contractuelle à propos d'une nouvelle étude sur la matière", Revue Trimestrale Droit Civile, pp. 712 y ss.

- SApone, N. (2008). La responsabilità precontrattuale, Milán: Giuffrè.

- Schmidt, J. (1982). Negotiation et conclusion de contrats, Paris: Dalloz.

- Schulze, R. / Schulte-Nölke, H. (dirs.) (2002). European Contract Law in Comnunity Law, Köln: Bundesanzeiger.

- Schulze, R. (2006). "Deberes precontractuales y conclusión del contrato en el Derecho contractual europeo", Anuario de Derecho Civil, tomo LIX, vol. 1, pp. 29-58.

- VAN ERP, J.H.M. (1998). “The precontractual stage”, en Hartkamp et alii: Towards an European Civil Code, Nijmegen-The HagueLondon-Boston: Ars Aequi, pp. 363 y ss.

- (2003). "European "culpa in contrahendo" doctrine? Towards a model of contract as a legal relationship and situation-specific duties to inform", en Spiau Spiau, Santiago / Vaquer Aloy, Antoni (eds.): Bases de un Derecho contractual europeo, Valencia: Tirant lo Blanch, pp 67-77. 
- Von Bar, Christian et alii (eds.) (2008). Principles. Definitions and Model Rules of European Private Law. Draft Common Frame of Reference (DCFR). Interim Outline Edition preparada por el Study Group on European Civil Code y el Research Group on EC Private Law, Munich: ed. Sellier - European Law Publishers.

- Von Bar, Christian (2005). "Working together toward a Common Frame of Reference", JI (Juridica International), No X, pp. 17-26.

- Von Jhering, R. (1861). "Culpa in contrahendo oder Schadensersatz bei nichtigen oder nicht zur Perfektion gelangten Verträgen”, Jherings Jahrbücher für die Dogmatik des heutigen römischen und deutschen Privatrechts, No 4, pp 1-113.

- Whittaker, S. / Zimmermann, R. (dirs.) (2000); Kötz, K. (1998). "Towards a European Civil code: the duty of good faith", en Cane, P. / Stapleton, J.: The Law of obligations. Essays in celebration of John Fleming, Oxford: Clarendon Press, pp. 243-259.

Cambridge University Press. (2000). Good faith in European Contract Law, Oxford:

- Winkel, L. (2002). "Culpa in contrahendo in Roman law and in some modern Dutch court decisions", en VV. AA: Viva vox iuris romani. Essays in honour of Johannes Emil Spruit, Amsterdam: Gieben, pp. 149-157.

- Zahn, Y. / Machteld, J. / Rook, S. /Poissonnet, A.S. (2007). "Withdrawing from pre-contractual negotiations and the duty of good faith- harmonising European views", Ars Aequi, No 56, pp. 487-494.

- Zimmermann, R. (1996). The law of obligations. Roman Foundations of the Civilian Tradition, Oxford: Clarendon Press. 